\title{
Abnormal uterine bleeding in peri-menopausal age: An observational study
}

\author{
Anupma Kumari', Raj Kumar,"* \\ ${ }^{1,2}$ Senior Resident, ${ }^{1}$ Dept. of Obstetrics and Gynecology, ${ }^{2}$ Dept. of Orthopaedics, All India Institute of Medical Sciences, \\ Rishikesh, Uttarakhand, India
}

*Corresponding Author: Raj Kumar

Email: drraj11081983@gmail.com

Received: $6^{\text {th }}$ May, 2018

Accepted: $12^{\text {th }}$ August, 2018

\begin{abstract}
Introduction: Abnormal Uterine Bleeding (AUB) is a term which refers to menstrual bleeding of abnormal frequency, duration or quantity. It is a common gynecological complaint accounting one third of outpatient visits to gynecologist. It is caused by wide variety of organic or non-organic causes. The aim of this study was to find out incidence of abnormal uterine bleeding with respect to aetiopathology, age, parity, marital status, treatment options and other medical disorders.

Materials and Methods: This study included prospective study of randomly selected 180 cases of abnormal uterine bleeding between 40-55 years of age during April 2015 to July 2016, in the Dept. of Obstetric \& Gynaecology, NMCH, Patna. Details of each patient's were recorded and analysed with respect to aetiopathology, age, parity, marital status, socioeconomic status, treatment options and other medical disorders. Patients were evaluated with menstrual history, physical examination, laboratory tests, imaging studies and histological examinations. Patients were followed up from 3 to 8 months with an average of about 4.5 months.

Results: Most common age group presenting with AUB was 40-45 years (65.55\%) and mostly (68.33\%) belonged to low socioeconomic status. Most of the women were multiparous and menorrhagia was most common presentation. In $51.66 \%$ cases, cause was non-organic (dysfunctional uterine bleeding) and among organic causes fibroid (28.88\%) uterus was most common. Bulky uterus was found in $41.11 \%$ of cases and $43.33 \%$ had proliferative endometrium. Majority of patients had mild anemia. Maximum number of patients (70.55\%) were treated surgically and $27.77 \%$ got medical treatment.

Conclusion: Abnormal uterine bleeding (AUB) is a common gynecological complaint associated with considerable morbidity and significantly affects the patient's family, personal and social life. Perimenopausal women's health and quality of life can be maintained and improved through preventive care, life style modification, early diagnosis of risk factor or disease and appropriate treatment.
\end{abstract}

Keywords: Abnormal uterine bleeding, Perimenopausal women, Endometrium.

\section{Introduction}

Perimenopausal age of a women's life is still an enigma. In 2001, Stages of reproductive aging workshop (STRAW) defined perimenopause as the beginning with menopausal transition and ending 12 months after the last menstrual period. It is associated with menstrual and endocrinal alteration and may lasts for many years (2 to 8 years). ${ }^{1}$ It can be associated with a wide spectrum of disorders, but very little research has been done on this subject.

Abnormal uterine bleeding is one of the most common health problem encountered by women of perimenpausal age group. It accounts for two-thirds of all hysterectomies worldwide, thereby a great cause of morbidity and mortality in this age group. ${ }^{2}$ It accounts for about $5-10 \%$ of cases in the outpatient clinic setting. About $20 \%$ of affected individuals are in the adolescent age group, and 50\% of affected individuals are aged 4050 years. ${ }^{3}$ If the treatment is not instituted early, it can lead to severe anemia. If blood loss is acute, it can result in hypovolemic shock and the patient may collapse if the bleeding is too severe.

The most common cause of AUB is dysfunctional uterine bleeding (DUB) which has no any detectable organic cause. It is usually due to hormonal disturbances: reduced level of progesterone causes low levels of prostaglandin F2alpha and cause menorrhagia (abnormally heavy flow); increased levels of tissue plasminogen activator (a fibrinolytic enzyme) lead to more fibrinolysis. Organic causes of AUB includes benign pelvic lesion (fibroid, adenomyosis, cervical and endometrial polyp, tuberculosis), infection, trauma, iatrogenic (hormonal replacement therapy, contractive use, anticoagulant therapy), malignancy of cervix, endometrium or ovary, systemic illness (hypertension, diabetes mellitus, thyroid disorders), etc. AUB can be classified as ovulatory or anovulatory, depending on whether ovulation is occurring or not. ${ }^{4}$

The investigation of a patient with AUB in perimenopausal age begins only after thorough history, general physical examination and systemic evaluation. Apart from routine investigations, PAP smear, saline infusion salpingography, endometrial sampling, pelvic ultrasound and hysteroscopy should be done routinely. Hysteroscopy combined with guided biopsy has been considered as gold standard in the evaluation of AUB. Ultrasound is a safe initial investigation in the management of abnormal uterine bleeding as it is a noninvasive procedure for the detection of endometrial pathology. Dilatation and Curettage (D and C) is the mainstay of endometrial sampling since a long time. ${ }^{2,5}$ 
Once malignancy and significant pelvic pathology have been ruled out, medical treatment is an effective first line therapeutic option for abnormal uterine bleeding. Medical treatment tailored to the individual woman's therapeutic goals, desire for contraception, underlying medical conditions, and tolerance of side effects will encourage compliance and maximize the likelihood of treatment success. Effective medical treatment options include Non-hormonal (Non-steroidal anti-inflammatory drugs, Antifibrinolytics) and Hormonal (Combined hormonal contraceptives, Levonorgestrel-releasing intrauterine system, Oral progestins (long phase, days 5 to 26), Depotmedroxyprogesterone acetate, Danazol, GnRHagonists). ${ }^{6}$

Improvement in quality of life is the ultimate goal of treatment and may occur through achieving eumenorrhea or amenorrhea. Surgical options for managing AUB depend on several factors including the patient's expectations and uterine pathology. Surgical options include dilation and uterine curettage, hysteroscopic polypectomy, endometrial ablation, myomectomy, and hysterectomy. ${ }^{6}$

\section{Materials and Methods}

This prospective observational study of 180 cases of abnormal uterine bleeding between 40-55 years of age, attended to OPD \& Gynae emergency was conducted during April 2015 to July 2016, in the Dept. of Obstetric \& Gynaecology, NMCH, Patna. Hospital ethical committee approval was obtained to conduct the study and a valid written consent was taken from all the cases. A detailed history was taken and a thorough clinical examination was done, complemented by relevant investigation as required for the study. All the data were duly recorded in the standard prepared proforma. Details of each patient's were recorded and analysed with respect to aetiopathology, age, parity, marital status, socioeconomic status, treatment options and other medical disorders. All perimenopausal (40 to 55 year) women presenting with abnormal uterine bleeding were included and women with active or recent pelvic inflammatory disease, patient in menstruation phase, pregnancy or suspected pregnancy complications and cervical stenosis were excluded from the study. Patients were followed up from 3 to 8 months with an average of about 4.5 months.

\section{Observation and Results}

In our observational study, randomly selected 180 patients, who attended to Gynae. OPD and emergency during study period, were studied.

Out of 180 patients studied, 118 (65.55\%) cases were in the age group of 40 to 45 years followed by 50 $(27.77 \%)$ cases in 46 to 50 years and $12(6.66 \%)$ in 51 to 55 years of age. Majority $(n=136,75.55 \%)$ of patients were Hindu, 31 (17.22\%) were Muslim and 13 (7.22\%) belonged to other religions. 123 (68.33\%) cases belonged to low socioeconomic status, 46 $(25.55 \%)$ to middle and $11(6.11 \%)$ to high class.

Table 1: Age distribution of AUB cases

\begin{tabular}{|l|c|c|}
\hline Age Group (years) & No. of Cases & Percentage (\%) \\
\hline $40-45$ & 118 & 65.55 \\
\hline $46-50$ & 50 & 27.77 \\
\hline $51-55$ & 12 & 6.66 \\
\hline
\end{tabular}

It is evident from our study that AUB was much more common in multiparus women than in nulliparus. Out of 180 cases, $173(96.11 \%)$ belonged to para 1 and above, and among these, AUB was more common in para 1-3 (71.11\%). $177(98.33 \%)$ patients were married while 3 were unmarried. $149(82.77 \%)$ cases reported within 1 year, $22(12.22 \%)$ between 1 to 2 year and 9 $(5 \%)$ after 2 years of suffering.

Table 2: Distribution of cases according to parity.

\begin{tabular}{|l|c|c|}
\hline \multicolumn{1}{|c|}{ Parity } & No. of Cases & Percentage (\%) \\
\hline Para 0 & 7 & 3.88 \\
\hline Para 1-3 & 128 & 71.11 \\
\hline Para 4 \& above & 45 & 25 \\
\hline
\end{tabular}

In the present study, no organic cause could be found in $93(51.66 \%)$ cases and were labeled as DUB after proper investigation. Organic causes were found in $87(48.33 \%)$ cases. Among organic causes, uterine fibroid was seen in $52(28.88 \%)$ cases, adenomyosis in $7(3.88 \%)$, pelvic inflammatory disease (PID) in 6 $(3.33 \%)$, endometrosis in $5(2.77 \%)$, $\mathrm{H}$. mole in 3 $(1.66 \%)$ and endometrial carcinoma in $2(1.11 \%)$ cases. Rest of the causes attributed only 6 to $7 \%$ of cases. 2 cases of carcinoma cervix were found which were multiparous, belonging to Hindu religion and low socioeconomic status. Both cases of endometrial carcinoma were obese, and having type 2 diabetes mellitus and hypertension. 2 cases of AUB had associated hypothyroidism.

Table 3: Aetiology of various organic causes

\begin{tabular}{|l|c|c|}
\hline \multicolumn{1}{|c|}{ Aetiology } & $\begin{array}{c}\text { No. of } \\
\text { Cases }\end{array}$ & $\begin{array}{c}\text { Percentage } \\
(\mathbf{\%})\end{array}$ \\
\hline Fibroid & 52 & 28.88 \\
\hline Adenomyosis & 7 & 3.88 \\
\hline $\begin{array}{l}\text { Pelvic inflammatory } \\
\text { disease }\end{array}$ & 6 & 3.33 \\
\hline Endometriosis & 5 & 2.77 \\
\hline H. mole & 3 & 1.66 \\
\hline Endometrial carcinoma & 2 & 1.11 \\
\hline Cervical carcinoma & 2 & 1.11 \\
\hline Cervical polyp & 2 & 1.11 \\
\hline Endometrial ploy & 2 & 1.11 \\
\hline Hypothyroidism & 2 & 1.11 \\
\hline $\begin{array}{l}\text { Tuberculous } \\
\text { endometritis }\end{array}$ & 2 & 1.11 \\
\hline Ovarian tumour & 1 & 0.55 \\
\hline IUCD & 1 & 0.55 \\
\hline
\end{tabular}


It was observed that commonest bleeding pattern in our series was menorrhagia (43.88\%). Metrorrhagia accounted for $28.88 \%$ of cases. Polymenorrhoea and polymenorrhagia were seen in $33(18.33 \%)$ and 14 $(7.77 \%)$ cases respectfully.

Table 4: Pattern of various menstrual irregularities in AUB cases

\begin{tabular}{|l|c|c|}
\hline Bleeding pattern & $\begin{array}{c}\text { No. of } \\
\text { Cases }\end{array}$ & $\begin{array}{c}\text { Percentage } \\
(\mathbf{\%})\end{array}$ \\
\hline Menorrhagia & 79 & 43.88 \\
\hline Metrorrhagia & 52 & 28.88 \\
\hline Polymenorrhoea & 33 & 18.33 \\
\hline Polymenorrhagia & 14 & 7.777 \\
\hline Continuous bleeding & 2 & 1.11 \\
\hline
\end{tabular}

Maximum number of patients $(53.33 \%)$ in this study had mild anaemia with haemoglobin 10 to 10.9 gm\%. $43(23.88 \%)$ cases were having acceptable level of haemoglobin. Moderate degree anaemia was present in $29(16.11 \%)$ cases and $12(6.66 \%)$ case had severe anaemia.

Table 5: Association of anemia in AUB

\begin{tabular}{|l|c|c|}
\hline Hb in gm\% & No. of Cases & $\begin{array}{c}\text { Percentage } \\
(\%)\end{array}$ \\
\hline$>\mathrm{Hb}$ in & 43 & 23.88 \\
\hline $10-10.9$ & 96 & 53.33 \\
\hline $7-9.9$ & 29 & 16.11 \\
\hline$<7.0$ & 12 & 6.66 \\
\hline
\end{tabular}

Clinical examination in our study revealed bulky uterus in $74(41.11 \%)$ cases and cystic ovaries in 42 $(23.33 \%)$ cases. These findings were frequently seen in patients with menorrhagia.

Histopathological examination of endometrium obtained from diagnostic curettage as well as from hysterectomy specimen revealed proliferative endometrium in $78(43.33 \%)$ cases and secretory in 51 $(28.33 \%)$. In $38(21.11 \%)$ cases, endometrium was hyperplastic and in $4(2.22 \%)$ cases, endometrium had irregular shedding. Atrophic endometrium was found in $3(1.66 \%)$ and in $2(1.11 \%)$ cases endometrial carcinoma was detected.

Table 6: Endometrial pattern in AUB cases

\begin{tabular}{|l|c|c|}
\hline Endometrial pattern & $\begin{array}{c}\text { No of } \\
\text { cases }\end{array}$ & $\begin{array}{c}\text { Percentage } \\
(\mathbf{\%})\end{array}$ \\
\hline Proliferative & 78 & 43.33 \\
\hline Secretory & 51 & 28.33 \\
\hline Hyperplastic & 38 & 21.11 \\
\hline Irregular shedding & 4 & 2.22 \\
\hline Atrophic & 3 & 1.66 \\
\hline Endometrial polyp & 2 & 1.11 \\
\hline Endometrial carcinoma & 2 & 1.11 \\
\hline TB endometritis & 2 & 1.11 \\
\hline
\end{tabular}

Majority of cases $(n=127,70.55 \%)$ in our study treated surgically out of which 124 cases undergone hysterectomy. 2 patients undergone polypectomy \& diagnostic curettage, and 1 patient undergone dilatation \& curettage. Wertheim's hysterectomy was done in both cases of carcinoma cervix and extended hysterectomy in both cases of endometrial carcinoma. One case of DUB was treated by Ward Mayo operation because she had associated $2^{\circ}$ uterovaginal prolapsed. $50(27.77 \%)$ patients were treated with drugs depending on the cause of AUB and only 3 patients managed with reassurance, symptomatic relief and haematinics.

\section{Discussion}

A regular menstrutation has always been accepted as an indication of good reproductive health. A change in the amount, duration or regularity of this periodic loss is therefore regarded as something going wrong and not accepted by any women especially in the perimenopausal age.

In the present study, 180 women of perimenopausal age with abnormal uterine bleeding were studied. Majority $(n=136,75.55 \%)$ of patients were Hindu, 31 (17.22\%) were Muslim and 13 (7.22\%) belonged to other religions. $123(68.33 \%)$ cases belonged to low socioeconomic status, $46(25.55 \%)$ to middle and $11(6.11 \%)$ to high class. This appeared to be due to the fact that majority of patients were from lower class families. Affluent classes usually go to private clinic.

In this study, maximum number $(n=118,65.55 \%)$ of AUB cases were in the age group of 40 to 45 years followed by $50(27.77 \%)$ cases in 46 to 50 years and 12 $(6.66 \%)$ in 51 to 55 years of age. This finding varied with M. B. Swami et al. study which showed $53.60 \%$ cases in the age group of 40 to 45 years and $22.40 \%$ cases in 46 to 50 years of age. ${ }^{7}$ In their study, Urvashi Verma et al. showed $38 \%$ cases in the age group of $40-$ 43 years, $41 \%$ in $44-47$ years and $21 \%$ in $48-51$ years. ${ }^{8}$

$149(82.77 \%)$ cases reported within 1 year, 22 $(12.22 \%)$ between 1 to 2 year and $9(5 \%)$ after 2 years of suffering. This disparity may be due to ignorance and poor literacy rate in our population.

It is evident from our study that AUB is much more common in multiparous women than in nulliparous. Out of 180 cases, $173(96.11 \%)$ belonged to para 1 and above, and among these, AUB was more common in para $1-3(71.11 \%)$. This finding is comparable to the Kumar Suneet study which found $98 \%$ cases of AUB were multipara and $44 \%$ cases in para 1-3. ${ }^{9}$ However, Singh A et al. study showed that $92 \%$ cases of AUB were multipara and $8 \%$ were nullipara. ${ }^{10}$

In the present study, no organic cause could be found in $93(51.66 \%)$ cases and were labeled as DUB. Organic causes were found in $87(48.33 \%)$ cases. Among organic causes, uterine fibroid was most common cause, seen in $52(28.88 \%)$ cases followed by 
adenomyosis ( $n=7,3.88 \%)$. Other causes of AUB included pelvic inflammatory disease $(\mathrm{n}=6,3.33 \%)$, endometrosis $(n=5,2.77 \%), H$. mole $(n=3,1.66 \%)$ and endometrial carcinoma $(n=2,1.11 \%)$. Katke RD CC et al. showed that $43.9 \%$ patients were having fibroid as associated pathology on Ultrasound. ${ }^{11}$ Purandre et al. (1993) in a series of 518 patients observed organic pathology in $37 \%$ of the cases and $63 \%$ patients were having without any organic pathology. Their study was mainly on cases of DUB but our study is based on all cases of AUB. So, in our study incidence of organic causes is more. Diachman \& Mackles (1965) and Chaudhary et al. (1981) also found that majority of perimenopausal cases with AUB had no organic pathology. This is probably due to alteration in Hypothalamic-Pituitary-Ovarian function preceding menopause.

It was observed that commonest bleeding pattern in our series was menorrhagia $(n=79,43.88 \%)$. Metrorrhagia accounted for $28.88 \%$ of cases. Polymenorrhoea and polymenorrhagia were seen in 33 (18.33\%) and 14 (7.77\%) cases respectfully. Katke RD $\mathrm{CC}$ et al. also found menorrhagia as the commonest pattern of AUB in perimenopausal age, occurring in $74.24 \%$ of cases. Other pattern of AUB they found are polymenorrhagia $(10.60 \%)$, metrorrhagia $(6.06 \%)$ and poly-menorrhea $(4.50 \%) .{ }^{11}$ Our observation correlates well to the findings of Sharma et al. (1991) and Bidye et al. (1993) studies. They observed that maximum number of AUB cases were of menorrhagia. Kotagasti et al. study found menorrhagia (33\%) as the commonest bleeding pattern in AUB, followed by oligomenorrhoea $(19.97 \%)$ and polymenorrhoea $(18.35 \%) .^{12}$

Maximum number of patients $(\mathrm{n}=96,53.33 \%)$ in this study had mild anaemia with haemoglobin 10 to $10.9 \mathrm{gm} \% .43(23.88 \%)$ cases were having acceptable level of haemoglobin. Moderate degree anaemia was present in $29(16.11 \%)$ cases and $12(6.66 \%)$ case had severe anaemia. Bidyae (1993) and Gahlot et al. (1993) showed $34 \%$ and $88.64 \%$ cases of AUB having mild anaemia respectfully. Nahid Sultana et al. showed that about $60 \%$ patients had hemoglobin level less than 50\% and only $20 \%$ patients had hemoglobin level more than $60 \% .{ }^{13}$

Clinical examination in our study revealed bulky uterus in $74(41.11 \%)$ cases and cystic ovaries in 42 (23.33\%) cases. Nahid Sultana et al. showed that $72 \%$ cases of DUB had bulky uterus and $18 \%$ patients had cystic ovary. ${ }^{13}$

Histopathological examination of endometrium in our study revealed proliferative endometrium in 78 $(43.33 \%)$ cases and secretory in $51(28.33 \%)$. In 38 $(21.11 \%)$ cases, endometrium was hyperplastic and in 4 $(2.22 \%)$ cases endometrium had irregular shedding. Atrophic endometrium was found in $3(1.66 \%)$ and in 2 $(1.11 \%)$ cases endometrial carcinoma was detected. Katke RD et al. showed proliferative endometrium in $46.90 \%$ cases, secretory in $40.90 \%$, hyperplastic in
$6.00 \%$, irregular shedding in $1.50 \%$ and atrophic in $1.66 \%$ cases of AUB in perimenopausal women. ${ }^{11}$ Kumar Suneet study showed proliferative endometrium in $36 \%$ cases, secretory in $24 \%$, hyperplastic in $16.00 \%$ and atrophic in $14 \%$ cases. $^{9}$

In our study, majority of cases $(n=127,70.55 \%)$ of AUB were treated surgically out of which 124 cases undergone hysterectomy. 2 patients undergone polypectomy \& diagnostic curettage, and 1 patient undergone dilatation \& curettage. Wertheim's hysterectomy was done in both cases of carcinoma cervix and extended hysterectomy in both cases of endometrial carcinoma. After surgical treatment, carcinoma cervix cases were referred to oncology department for further management. One case of DUB was treated by Ward Mayo operation because she had associated $2^{\circ}$ uterovaginal prolapsed. $50(27.77 \%)$ patients were treated with drugs depending on the cause of AUB and 3 patients were managed on expectant line with only reassurance, symptomatic relief and haematinics. Reich $\mathrm{H}$ et al. showed that hysterectomy is the definitive treatment for DUB and has a higher rate of patient satisfaction..$^{14} 50 \%$ rate of hysterectomy was reported by Gath et al. (1987) in the management of perimenopausal DUB.

In developing countries like ours, where most of the women do not return for follow up and are not dependant for hormonal therapy, hysterectomy will be the best choice (Ratnam, 2001). Removal of uterus is usually psychologically much more acceptable provided the patient has been fully consulted and counseled.

\section{Conclusion}

Although perimenopause is largely unstudied, many therapeutic approaches to the management of perimenopausal disturbances exist, both prescription and non-prescription. The perimenopausal women's health and quality of life can be maintained \& improved through preventive care, lifestyle modification, early diagnosis of disease or increased risk for disease and intervention when appropriate. AUB may be due to malignancy of genital tracts. Our clinical goal should be to optimize the women health during and after perimenopause.

\section{References}

1. Soules MR, Sherman S, Parrott E. Stages of reproductive aging (STRAW). J Womens Health Gender Based Med. 2001;10(9):843-848.

2. Parul Kotdawala, Sonal Kotdawala, Nidhi Nagar. Evaluation of endometrium in peri-menopausal abnormal uterine bleeding. J Midlife Health. 2013;4(1):16-21.

3. Rezk M, Masood A, Dawood R. Perimenopausal bleeding: Patterns, pathology, response to progestins and clinical outcome. J Obstet Gynaecol. 2015;35(5):517-21.

4. VG Padubidri, SN Daftray: Shaw's textbook of Gynaecology/ 16 ${ }^{\text {th }}$ edition/chapter 24/page335-348. 
5. Richard J. Gimpelson, Thomas R. Whalen. Hysteroscopy as gold standard for evaluation of abnormal uterine bleeding. Am J Obstet Gynecol. 1995;173(5):1637-8.

6. Janet R. Albers, Sharon K. Hull, and Robert M. Wesley: Abnormal Uterine Bleeding. Am Fam Physician. 2004;69(8):1915-1926.

7. M. B. Swami. Histopathological evaluation of endometrium in pre and postmenopausal uterine bleeding. Indian Journal of Obstetrics and Gynaecology Research. 2015;2(4):264-269.

8. Urvashi Verma. Diagnostic approach in perimenopausal woman with abnormal uterine bleeding. Journal of South Asian Federation of Menopause Socities, 2014;2(1):1214.

9. Kumar Suneet. Clinicopathological Study of Abnormal Uterine Bleeding in North Indian Patients. Asian Journal of Biomedical and Pharmaceutical Sciences. 2016;6(53):50-51.

10. Singh A. Study of histopathological pattern of endometrium in abnormal uterine bleeding and its management. Int J Reprod Contracept Obstet Gynecol. 2016;5(2):432-436.
11. Katke RD, Zarariya AN. Use of diagnostic hysteroscopy in abnormal uterine bleeding in perimenopausal age group and its clinicopathological co-relation with ultrasound and histopathology findings: experience in a tertiary care institute. Int J Reprod Contracept Obstet Gynecol. 2015;4:413-8.

12. Kotagasti. Prevalence of different menstrual irregularities in women with abnormal uterine bleeding (aub) - an observational study. Int J Cur Res Rev. 2015;7(10):66-70.

13. Nahid Sultana. Bulky Uterus and Multiparity are Important Contributing Factors for Dysfunctional Uterine Bleeding among Bangladeshi Women. Journal of Enam Medical College. 2016;6(1):23-27.

14. Reich H. Hysterectomy as treatment for dysfunctional uterine bleeding. Baillieres Best Pract Res Clin Obstet Gynaecol. 1999;13(2):251-69.

How to cite this article: Kumari A, Kumar R. Abnormal uterine bleeding in peri-menopausal age: An observational study. Indian $\mathrm{J}$ Obstet Gynecol Res. 2018;5(4):539-543. 